\title{
Influência da Corrente sobre o Rendimento Bruto de Fusão em Soldagem MIG/MAG
}

\author{
(Influence of Current on the Gross Fusion Efficiency in MIG/MAG Welding)
}

\author{
Edson Kazuo Hirata ${ }^{l}$, Luiz Felipe Beltzac ${ }^{l}$, Paulo César Okimotol, Américo Scotti ${ }^{l}$ \\ ${ }^{1}$ Universidade Federal do Paraná, Departamento de Engenharia Mecânica, Curitiba, Paraná, Brasil \\ okimoto@ufpr.br,scotti@ufpr.br
}

\begin{abstract}
Resumo
O objetivo deste trabalho foi estudar a influência da corrente de soldagem sobre o rendimento bruto de fusão em soldagem MIG/MAG, levando-se em consideração as dimensões da peça. Para isto, foram feitas soldagens sobre chapas de três espessuras em uma faixa de corrente, utilizando-se o processo MIG/MAG CMT com o auxílio de uma unidade robótica. A escolha desse processo se deu para minimizar o efeito mecânico do arco no rendimento bruto de fusão, fato experimentalmente comprovado no trabalho. Foi verificado que o aumento da corrente elou redução da combinação espessura-largura da chapa fazem aumentar o rendimento bruto de fusão. Mas a intensidade do efeito da corrente depende da combinação espessura-largura da chapa.
\end{abstract}

Palavras-chave: Soldagem, Rendimento bruto de fusão, CMT (Cold Metal Transfer).

Abstract: The objective of the present paper was to study the influence of the welding current on the gross fusion efficiency in MIG/ $M A G$ welding, taking into account the plate dimensions. A series of weldments were carried out over three thickness plates in a current range utilizing the MIG/MAG CMT process, aided by a robotic unity. The choice of the process aimed to minimize the arc mechanical effect on the gross fusion efficiency, fact experimentally checked in the work. It was verified that an increase of current and/or reduction in the thickness-width combination leads to higher gross fusion efficiency. However, the intensity of the current effect depends on the thickness-width combination

Key-words: Welding, Gross fusion efficiency, CMT (Cold Metal Transfer).

\section{Introdução}

Para fundir um metal a partir da temperatura ambiente, é necessário fornecer uma certa quantidade de calor suficiente para elevar a temperatura do metal sólido até o seu ponto de fusão (calor sensível) e adicionar uma parcela suficiente para converter o metal sólido em líquido já no ponto de fusão (calor latente). A norma A3.0 [1] da Sociedade Americana de Soldagem define o calor imposto como a energia entregue para a peça. Apesar de ser um termo normatizado, existe ainda na literatura uma certa imprecisão no uso das terminologias "energia de soldagem" e "calor imposto". O primeiro se refere à energia que se consome pelo arco durante a soldagem, quantificada pela razão da potência elétrica com a velocidade de soldagem. O calor imposto é a parcela da energia de soldagem que se transfere para a chapa, descontando, portanto, da energia de soldagem o calor perdido para o meio ambiente (perda esta normalmente referenciada como rendimento térmico). Ou seja, calor imposto é o produto

Recebido em 21/10/2013, texto final em 06/05/2014.

DOI: 10.1590/0104-9224/SI1902.08 da energia de soldagem com o rendimento térmico. O calor de fusão, por outro lado, é relacionado como a parcela do calor imposto na chapa que é efetivamente utilizado para fundir o material [2]. Esse parâmetro é de extrema importância do ponto de vista da capacidade de produção de um dado processo, pois é correlacionado com a eficiência do calor para formar um cordão de solda. Desta forma, neste trabalho define-se rendimento de fusão em soldagem como a razão entre a quantidade de calor cedida pelo arco efetivamente consumida para fundir o metal e o calor total imposto pelo arco.

Assim, a otimização operacional dos processos de soldagem a arco está diretamente ligada ao rendimento de fusão. Quanto maior o rendimento de fusão, maior volume de solda se forma com uma mesma energia despendida. Sabe-se que em geral quanto maior a energia de soldagem, também maior o volume da poça fundida. E a energia de soldagem pode ser aumentada tanto pelos parâmetros elétricos/velocidade da fonte de calor como pelo gás de proteção. Por exemplo, Schwedersky et al. [3] mostraram que quanto maior o teor de $\mathrm{H}_{2}$ em mistura com Ar no processo TIG, maior foi o rendimento de fusão e maior a eficiência do processo, possibilitando a elevação da velocidade de soldagem. Entretanto, não se pode dizer que quanto maior o volume de um cordão maior seria o rendimento de fusão. Isto porque a formação do cordão é um fenômeno complexo.

De acordo com Scotti e Ponomarev [4] (pp. 70-90), a 
formação do cordão é influenciada por dois efeitos, o efeito térmico e mecânico. A principal fonte de calor é gerada no acoplamento arco-peça, onde existe uma grande queda de tensão. Esse calor é transferido por condução para o metal de base, onde parte dele é responsável por fundir o material e parte é difundida para regiões ao redor da zona fundida. Outro fator que colabora com o efeito térmico é a entalpia dos gases de proteção, que, por convecção forçada devido ao jato de plasma, é transferida parcialmente para o metal de base. O calor das próprias gotas do metal de adição sendo transferidas também tem participação na formação do cordão.

Ainda para Scotti e Ponomarev [4], o jato de plasma e a pressão devida ao campo magnético sobre a superfície da poça são fatores importantes que caracterizam o efeito mecânico. $\mathrm{O}$ jato de plasma é formado pela diferença de pressão ao longo do eixo do arco. Como a passagem de corrente não se dá de maneira homogênea ao longo do arco, passa a existir mais corrente passando por uma seção transversal do arco próxima ao eletrodo do que numa seção com o mesmo raio próxima à chapa sendo soldada. Assim, a força magnética gerada será maior próxima ao eletrodo do que da chapa. O tamanho do arco também não é constante ao longo do seu eixo. Como o seu raio é menor junto ao eletrodo, resulta-se numa pressão maior próximo ao eletrodo do que à chapa. Assim, irá surgir o jato de plasma com sentido do eletrodo para a chapa. Além da força exercida pelo jato de plasma sobre a poça fundida (pressão dinâmica), existe a pressão estática devido às forças magnéticas geradas. Essa combinação de pressões (estática e dinâmica) faz com que a superfície da poça fundida sofra uma deflexão na direção do metal de base (permitindo que a ação térmica se dê mais no fundo da poça do que sobre a superfície da mesma). As gotas em transferência também influenciam no efeito mecânico, segundo Scotti e Rodrigues [5]. Ao serem projetadas em direção do metal de base, essas gotas possuem uma certa quantidade de movimento. Ao se chocarem com a superfície da poça, essa quantidade de movimento é transferida da gota para a poça.

Ao se aumentar a corrente de soldagem, os efeitos térmicos e mecânico são intensificados. Do ponto de vista térmico, quanto maior a corrente, maior é o calor gerado no acoplamento arco-poça. Deve-se também pensar neste contexto no efeito da concentração de corrente (controlada tanto pelo tipo de gás de proteção como pelo comprimento do arco). Também irá ocorrer um aumento no volume do arco, o que significa mais energia acumulada na forma de calor transferido. Finalmente, apesar do tamanho das gotas diminuir quando se aumenta a corrente, a frequência de transferência e a própria quantidade de material se torna maior, consequentemente também mais calor transferido para a chapa. Do ponto de vista mecânico, quanto maior a corrente, mais intenso será o jato de plasma. Isso significa tornar o efeito térmico do acoplamento arco-peça mais efetivo ao afastar a poça que se encontra entre o arco e a peça. Além disso, a capacidade de transferência de calor (que se encontra na coluna de plasma) por convecção forçada será maior. A pressão estática devido às forças magnéticas também será intensificada com o aumento da corrente. Maior corrente, dando origem a um campo magnético radial mais intenso, que, por sua vez, irá gerar forças magnéticas maiores, propiciando, assim, um melhor acoplamento arco-peça. A força com que as gotas em transferência são lançadas também será maior com aumento da corrente, tornando-se maior a quantidade de movimento transferida para a superfície da poça quando ocorrer o choque da gota com a poça.

Dessa forma, pode-se prever que com o aumento da corrente gera-se um volume de poça maior. Mas, paralelamente, faz aumentar a energia de soldagem. O rendimento de fusão, por sua vez, é mais dependente da difusão do calor na peça do que da energia imposta propriamente dita (já que não adianta o calor entrar se ele se difunde antes de conseguir aquecer um volume do material). Depende, além das propriedades do material de base (condutividade térmica, calor específico e ponto de fusão), da geometria da peça e da concentração do arco. Quanto maior o comprimento do arco, maior a área de acoplamento, diminuindo a concentração do calor e também o rendimento de fusão. $O$ efeito da interposição da poça de fusão entre o arco e o metal sob a poça também pode dificultar a transferência do calor para o metal de base. Assim, fica difícil estipular que um aumento de corrente signifique aumento do rendimento de fusão.

Para fins deste trabalho, se denomina de rendimento bruto de fusão a relação entre o calor consumido para fundir o material e a energia de soldagem despendida. Rendimento líquido seria a relação entre o calor consumido para fundir o material e o calor imposto. Isto por que calor imposto é apenas uma fração da energia de soldagem. Reis et al. [6] demonstraram, em um trabalho para determinar o comportamento do rendimento bruto de fusão em soldagem TIG frente a diferentes tipos de material de base, que o rendimento bruto de fusão é muito baixo (menor do que $10 \%$ ), mas tende a aumentar com a elevação do nível de corrente de soldagem (influência da dimensão da peça, que com o aumento do calor imposto favorece a saturação da condução de calor para a peça, favorecendo maior fusão do metal de base). Desta forma, demonstraram que o rendimento bruto de fusão do TIG depende não somente das propriedades termodinâmicas do material/parâmetros de soldagem, mas também das dimensões do material de base (maior calor imposto, mais evidente fica o efeito da espessura e/ou largura da chapa).

Entretanto, mesmo reconhecendo a importância do rendimento de fusão em soldagem, os trabalhos citados tratam o assunto de forma genérica ou especificamente para o processo TIG. Apesar de uma busca em bancos de dados convencionais, nada foi encontrado sobre rendimento de fusão aplicado ao processo MIG/MAG. Desta forma, o objetivo deste trabalho é estudar o efeito térmico da intensidade de corrente sobre o rendimento bruto de fusão no processo MIG/MAG, mas levando-se em conta o efeito da geometria do material de base.

\section{Materiais e Métodos}

Para se estudar o efeito da entrega térmica da corrente sobre o rendimento bruto de fusão, foram utilizadas soldagens de simples deposição sobre chapa ("bead-on-plate") em uma faixa de corrente típica de soldagem com transferência por curtocircuito, usando o processo MIG/MAG CMT. A escolha desse processo em especial se deu devido ao fato da transferência 
metálica ser por curto-circuito, evitando/minimizando, assim, os efeitos mecânicos das gotas em transferência e do jato de plasma (arco muito curto nesse processo). O CMT propicia uma transferência metálica bastante regular e com poucos respingos (evitando perdas térmicas por este efeito). Além disso, apresenta uma proporcionalidade muito grande entre tempo de arco aberto e em curto. $\mathrm{O}$ modo sinérgico desse processo possui a vantagem de manter o comprimento do arco constante para diferentes velocidades de alimentação e, consequentemente, para diferentes valores de corrente. Dessa maneira, o comprimento do arco tornou-se uma constante nesse estudo (ao aumentar a corrente, ocorre uma correção na tensão já programada na memória da máquina). Assim, garante-se estar trabalhando sempre na mesma característica estática do arco (mesmo comprimento de arco, independentemente da corrente). A curva escolhida para ser trabalhada dentro do modo sinérgico da máquina foi a C1362.

Para avaliar o efeito das dimensões do metal de base no estudo da influência da corrente sobre o rendimento bruto de fusão, três combinações espessura/largura de chapas foram usadas na mesma faixa de corrente. As dimensões das placas de teste (aço ABNT 1020) foram de $150 \times 38,2 \times 3 \mathrm{~mm}, 150$ x 72,0 × $13 \mathrm{~mm}$ e $150 \mathrm{~mm}$ × 50,8 $\mathrm{mm}$ x $25,4 \mathrm{~mm}$, sendo os cordões de $120 \mathrm{~mm}$ de comprimento. Uma distância bico de contato-peça (DBCP) de $11 \mathrm{~mm}$ e uma velocidade de soldagem de $5 \mathrm{~mm} / \mathrm{s}$ foram mantidas constantes durante os experimentos realizados, assim como o ângulo de ataque da tocha em $90^{\circ} \mathrm{em}$ relação ao plano horizontal. Para garantir a repetitividade nos movimentos e posicionamento da tocha durante as soldagens, foi utilizado um robô industrial. $\mathrm{O}$ metal de adição foi da classe AWS ER70S-6, com 1,2 mm de diâmetro, protegido com uma mistura de $\mathrm{Ar}+15 \% \mathrm{CO}_{2}$. A Tabela 1 apresenta as condições experimentais aplicadas na regulagem dos parâmetros, assim como os valores monitorados.

Depois de terminadas as soldagens, foram feitos cinco cortes transversais ao longo de cada cordão. As amostras foram lixadas e atacadas metalograficamente com Nital 10\%. Sobre as macrografias foram feitas medidas da área total do cordão $\left(\mathrm{A}_{\mathrm{f}}\right)$, da área da zona afetada pelo calor $(\mathrm{ZAC})$ e da penetração

Tabela 1 . Parametrização para regulagem das soldagens e parâmetros monitorados para avaliar a influência da corrente no rendimento bruto de fusão

\begin{tabular}{|c|c|c|c|c|c|}
\hline \multirow[b]{2}{*}{ Teste } & \multicolumn{2}{|c|}{ Valores de referência e regulado } & \multicolumn{3}{|c|}{ Valores Monitorados } \\
\hline & $\begin{array}{l}\text { Espessura-largura da } \\
\text { chapa }\left[\mathrm{m} \mathrm{x} 10^{-3}\right]\end{array}$ & $\begin{array}{c}\text { Velocidade de } \\
\text { Alimentação [m/min] }\end{array}$ & $\begin{array}{c}\text { Velocidade de } \\
\text { Alimentação [m/min] }\end{array}$ & Corrente Média [A] & Tensão Média [V] \\
\hline 01 & $3,0-38,2$ & 2,5 & 1,7 & 89.3 & 12.3 \\
\hline 03 & $3,0-38,2$ & 3,2 & 1,9 & 103.3 & 12.2 \\
\hline 07 & $3,0-38,2$ & 3,5 & 2,6 & 124.5 & 13.3 \\
\hline 08 & $3,0-38,2$ & 3,7 & 3,0 & 129.4 & 13.4 \\
\hline 05 & $3,0-38,2$ & 3,9 & 3,1 & 141.4 & 13.9 \\
\hline 06 & $3,0-38,2$ & 4,6 & 3,4 & 157.1 & 14.2 \\
\hline 09 & $3,0-38,2$ & 5,0 & 3,7 & 172.4 & 14.7 \\
\hline 04 & $3,0-38,2$ & 5,3 & 3,7 & 179.3 & 14.8 \\
\hline 02 & $3,0-38,2$ & 6,0 & 4,4 & 199.3 & 14.9 \\
\hline 10 & $3,0-38,2$ & 6,7 & 4,7 & 211.4 & 15.9 \\
\hline 11 & $3,0-38,2$ & 7,4 & 5,4 & 233.8 & 16.3 \\
\hline 12 & $12,8-72,0$ & 2,5 & 1,6 & 89.3 & 11,3 \\
\hline 13 & $12,8-72,0$ & 3,9 & 2,9 & 136.9 & 12,9 \\
\hline 31 & $12,8-72,0$ & 4,6 & 3,5 & 159.9 & 14.5 \\
\hline 14 & $12,8-72,0$ & 5,3 & 4,0 & 182.1 & 14,3 \\
\hline 32 & $12,8-72,0$ & 6,0 & 4,6 & 202.4 & 15.6 \\
\hline 33 & $12,8-72,0$ & 6,7 & 5,0 & 214.6 & 15.7 \\
\hline 15 & $12,8-72,0$ & 7,4 & 5,3 & 232.3 & 16.6 \\
\hline 27 & $25,4-50,8$ & 2.5 & 1.7 & 87.9 & 12.0 \\
\hline 26 & $25,4-50,8$ & 3.9 & 3.0 & 146.1 & 14.3 \\
\hline 28 & $25,4-50,8$ & 4.6 & 3.2 & 159.1 & 14.0 \\
\hline 25 & $25,4-50,8$ & 5.3 & 4.4 & 183.6 & 15.5 \\
\hline 29 & $25,4-50,8$ & 6.0 & 4.3 & 201.2 & 14.6 \\
\hline 30 & $25,4-50,8$ & 6.7 & 4.8 & 215.3 & 14.8 \\
\hline 24 & $25,4-50,8$ & 7.4 & 6.0 & 230.7 & 16.7 \\
\hline
\end{tabular}


linear do cordão. O rendimento bruto de fusão foi calculado pela Equação (1).

$\eta$ fusão $=\underline{\mathrm{Q}}_{\underline{\underline{f}}} \frac{\text { Vsold }}{\mathrm{P}_{\text {inst }}}$

onde Qf é o calor demandado para a fusão do cordão, ou seja, a somatória do calor sensível para o material atingir a temperatura de fusão a partir da temperatura ambiente e do calor latente de fusão do material (considerou-se desprezível o calor sensível de sobreaquecimento da poça), Vsold = velocidade de soldagem, que no caso foi mantida em $5 \mathrm{~mm} / \mathrm{s}, \mathrm{P}_{\text {inst }}=$ potência instantânea [7]. Qf, por sua vez, é calculado para as condições do presente estudo pela Equação (2).

$\mathrm{Q}_{\mathrm{f}}=\mathrm{r} \cdot \mathrm{A}_{\mathrm{f}} \cdot \mathrm{C}_{\mathrm{p}} \cdot\left(\mathrm{T}-\mathrm{T}_{0}\right)+\mathrm{r} \cdot \mathrm{A}_{\mathrm{f}} \cdot \mathrm{L}_{\mathrm{f}}$
Onde,

$\mathrm{Q}_{\mathrm{f}}=$ quantidade de calor requerida para fundir um certo volume de material;

$\mathrm{A}_{\mathrm{f}}=$ área da seção transversal do cordão (Tabela 2);

$\rho=$ densidade $\left(7870 \mathrm{~kg} / \mathrm{m}^{3}\right)$;

$\mathrm{C}_{\mathrm{p}}=$ calor específico do metal de base $\left(0,9 \mathrm{~J} / \mathrm{g}{ }^{\circ} \mathrm{C}\right)$;

$\mathrm{T}_{\mathrm{f}}^{\mathrm{p}}=$ temperatura de fusão $(1802,15 \mathrm{~K})$;

$\mathrm{T}_{0}=$ temperatura inicial $(298,15 \mathrm{~K})$;

$\mathrm{L}_{\mathrm{f}}=$ calor latente de fusão $(247 \mathrm{~J} / \mathrm{g})$.

$\mathrm{Na}$ Tabela 2 estão compilados os valores médios e respectivos desvios padrão medidos e calculados durante os testes para determinar a influência da corrente sobre o rendimento bruto de fusão, enquanto a Figura 1 ilustra os perfis em casos extremos.

Tabela 2. Rendimento bruto de fusão e geometria dos cordões obtidos para diferentes correntes e combinações espessura-largura das chapas de teste

\begin{tabular}{|c|c|c|c|c|c|c|c|c|c|c|}
\hline \multirow{2}{*}{ Teste } & \multirow{2}{*}{ 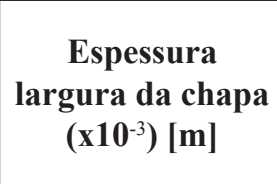 } & \multirow{2}{*}{$\begin{array}{l}\text { Corrente } \\
\text { Média [A] }\end{array}$} & \multicolumn{2}{|c|}{$\begin{array}{c}\text { Rendimento } \\
\text { Bruto de Fusão }\end{array}$} & \multicolumn{2}{|c|}{$\begin{array}{l}\text { Área transversal do } \\
\text { cordão }\left(\mathbf{x 1 0}^{-6}\right)\left[\mathrm{m}^{2}\right]\end{array}$} & \multicolumn{2}{|c|}{$\begin{array}{c}\text { Área da ZAC } \\
\left(\mathbf{x}^{-6}\right)^{-6}\left[\mathbf{m}^{2}\right]\end{array}$} & \multicolumn{2}{|c|}{ 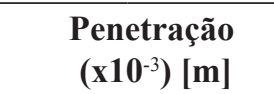 } \\
\hline & & & Média & $\begin{array}{l}\text { Desvio } \\
\text { Padrão } \\
\end{array}$ & Média & $\begin{array}{l}\text { Desvio } \\
\text { Padrão }\end{array}$ & Média & $\begin{array}{l}\text { Desvio } \\
\text { Padrão }\end{array}$ & Média & $\begin{array}{l}\text { Desvio } \\
\text { Padrão }\end{array}$ \\
\hline 1 & $3,0-38,2$ & 89.30 & 0,50 & 0,01 & 7,730 & 014 & 16,76 & 0,81 & 0,65 & 0,08 \\
\hline 3 & $3,0-38,2$ & 103.3 & 0,49 & 0,00 & 8,880 & 0,09 & 20,45 & 0,64 & 0,82 & 0,06 \\
\hline 7 & $3,0-38,2$ & 124.5 & 0,53 & 0,01 & 11,97 & 0,31 & 25,82 & 0,69 & 0,87 & 0,09 \\
\hline 8 & $3,0-38,2$ & 129.4 & 0,49 & 0,01 & 12,85 & 0,37 & 27,56 & 0,74 & 0,95 & 0,07 \\
\hline 5 & $3,0-38,2$ & 141.4 & 0,55 & 0,02 & 14,83 & 0,54 & 28,97 & 0,59 & 1,25 & 0,08 \\
\hline 6 & $3,0-38,2$ & 157.1 & 0,54 & 0,02 & 17,53 & 0,79 & 33,08 & 0,80 & 1,73 & 0,12 \\
\hline 9 & $3,0-38,2$ & 172.4 & 0,54 & 0,01 & 18,54 & 0,19 & 34,10 & 0,65 & 1,77 & 0,10 \\
\hline 4 & $3,0-38,2$ & 179.3 & 0,53 & 0,02 & 19,62 & 0,66 & 35,91 & 0,79 & 2,05 & 0,11 \\
\hline 2 & $3,0-38,2$ & 199.3 & 0,54 & 0,01 & 22,10 & 0,43 & 36,50 & 0,71 & 2,12 & 0,06 \\
\hline 10 & $3,0-38,2$ & 211.4 & 0,56 & 0,03 & 25,83 & 1,19 & 37,42 & 0,63 & 3,00 & 0,11 \\
\hline 11 & $3,0-38,2$ & 233.8 & 0,55 & 0,01 & 31,65 & 0,35 & 39,71 & 0,65 & 3,00 & 0,07 \\
\hline 12 & $12,8-72,0$ & 89.30 & 0,49 & 0,01 & 7,260 & 0,15 & 4,460 & 0,36 & 0,50 & 0,07 \\
\hline 13 & $12,8-72,0$ & 136.9 & 0,50 & 0,04 & 13,06 & 1,07 & 5,200 & 0,22 & 1,20 & 0,11 \\
\hline 31 & $12,8-72,0$ & 159.9 & 0,35 & 0,01 & 16,00 & 0,47 & 5,690 & 0,18 & 1,40 & 0,09 \\
\hline 14 & $12,8-72,0$ & 182.1 & 0,49 & 0,01 & 18,51 & 0,24 & 6,230 & 0,25 & 1,48 & 0,08 \\
\hline 32 & $12,8-72,0$ & 202.4 & 0,40 & 0,01 & 22,58 & 0,64 & 6,300 & 0,12 & 1,80 & 0,12 \\
\hline 33 & $12,8-72,0$ & 214.6 & 0,40 & 0,00 & 23,71 & 0,18 & 7,130 & 0,60 & 1,80 & 0,03 \\
\hline 15 & $12,8-72,0$ & 232.3 & 0,54 & 0,02 & 26,75 & 0,84 & 8,830 & 0,31 & 1,97 & 0,06 \\
\hline 27 & $25,4-50,8$ & 87.9 & 0,33 & 0,02 & 7,490 & 0,37 & 3,150 & 0,33 & 0,60 & 0,03 \\
\hline 26 & $25,4-50,8$ & 146.1 & 0,36 & 0,01 & 15,40 & 0,24 & 5,880 & 0,25 & 1,30 & 0,08 \\
\hline 28 & $25,4-50,8$ & 159.1 & 0,35 & 0,00 & 15,42 & 0,12 & 6,450 & 0,54 & 1,30 & 0,05 \\
\hline 25 & $25,4-50,8$ & 183.6 & 0,36 & 0,01 & 19,28 & 0,53 & 6,210 & 0,34 & 1,50 & 0,10 \\
\hline 29 & $25,4-50,8$ & 201.2 & 0,38 & 0,00 & 20,06 & 0,24 & 7,380 & 0,54 & 1,60 & 0,13 \\
\hline 30 & $25,4-50,8$ & 215.3 & 0,41 & 0,01 & 22,81 & 0,39 & 9,210 & 1,17 & 1,80 & 0,09 \\
\hline 24 & $25,4-50,8$ & 230.7 & 0,42 & 0,01 & 29,03 & 0,99 & 10,39 & 1,26 & 1,90 & 0,15 \\
\hline
\end{tabular}



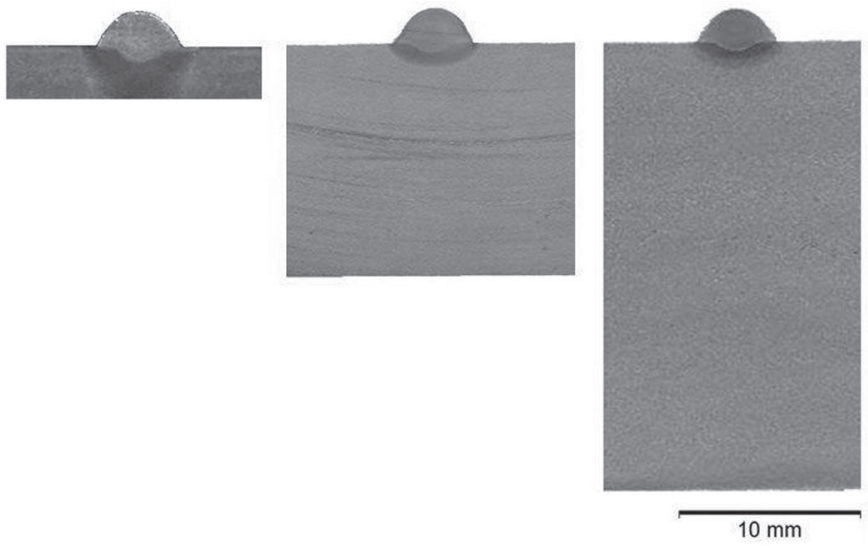

(a) Corrente baixa
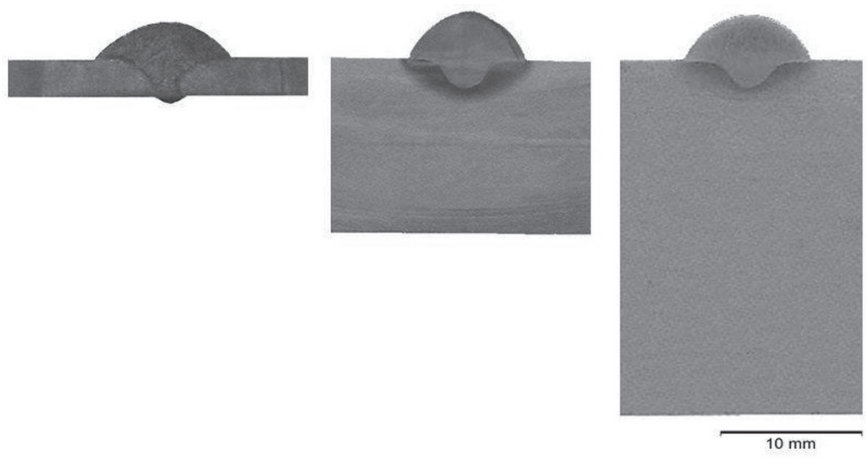

(b) Corrente alta

Figura 1. Perfis típicos dos cordões produzidos em duas faixas de corrente de soldagem para as diferentes espessuras de chapa utilizadas.

As Figuras 2 a 4 apresentam a relação entre a corrente e os parâmetros geométricos medidos para as três combinações espessura-largura. Com o aumento da corrente, aumentou-se o calor imposto, fato comprovado pelo aumento da área do cordão, aumento na penetração e aumento da área afetada pelo calor. Enquanto o aumento na área do cordão e na penetração foi linear, o crescimento da ZAC se apresentou não linear para chapas finas. Em relação à ZAC, com chapa de $3 \mathrm{~mm}$ de espessura, após um certo nível de corrente provavelmente começa a haver uma perda de calor proporcionalmente maior, ou seja, as perdas para o ambiente passam a ser mais significativas. Segundo Scotti et al.[2], quando a penetração é representativa em relação à espessura, uma parcela do calor imposto se perde na superfície oposta da chapa por radiação. Durante os experimentos foi possível visualmente observar que, ao aumentar a corrente de soldagem, a superfície de baixo das chapas com $3 \mathrm{~mm}$ de espessura foi ficando mais avermelhada durante as soldagens. Ou seja, maior quantidade de calor foi perdida para o ambiente por radiação. Já para as chapas mais grossas este fenômeno não ocorreu, pelo menos para o nível enérgico usado neste trabalho.

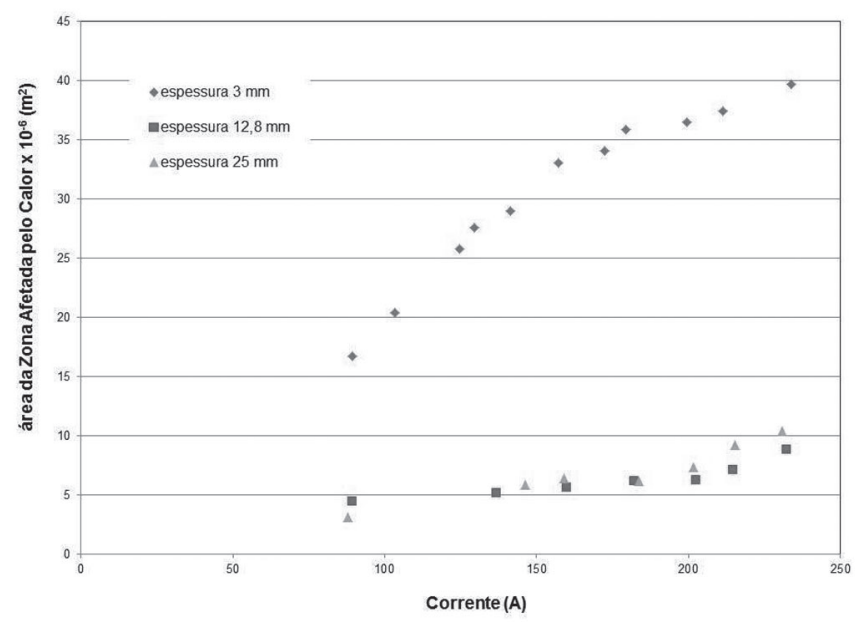

Figura 2 . Área da zona afetada pelo calor em função da corrente de soldagem para diferentes combinações espessuralargura de chapa

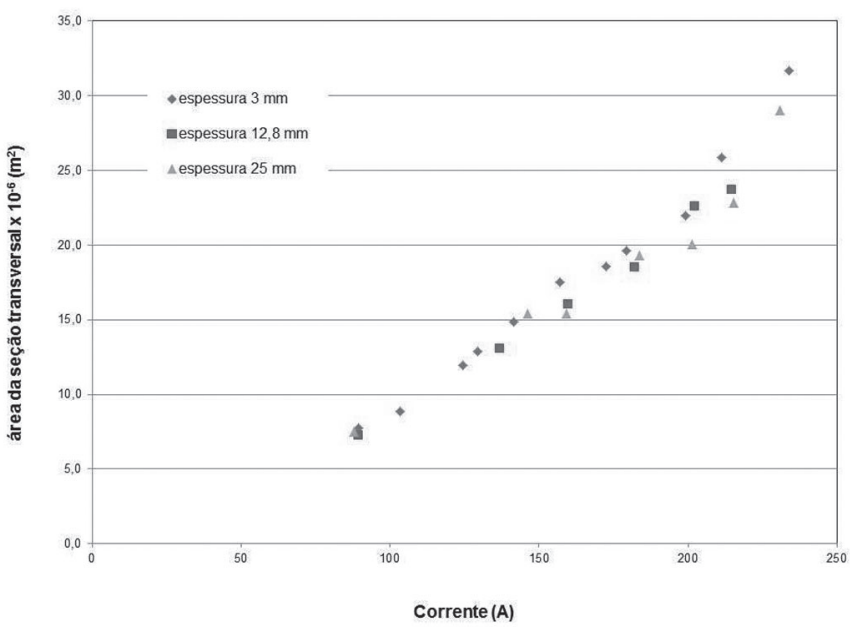

Figura 3. Área da seção transversal do cordão em função da corrente de soldagem para diferentes combinações espessuralargura de chapa

Seria de se esperar que nas chapas mais espessas $(12,8$ $\mathrm{mm}$ e $25,4 \mathrm{~mm}$ de espessura) se tivesse menor área de seção transversal do cordão e menor ZAC, devido à maior capacidade de dissipação de calor. A Figura 2 mostra que menores ZACs aconteceram para maiores espessuras. Entretanto, as áreas da seção transversal do cordão foram praticamente as mesmas para as três combinações espessura-largura de chapas utilizadas nos testes. Dois pontos justificam esse resultado. O primeiro seria que grande parte da área fundida em ambos os casos advém do material de adição (Figura 1), considerando que a taxa de deposição era a mesma (baixa sensibilidade para se inferir sobre o efeito da corrente). Mas não se pode desconsiderar a velocidade da frente de fusão em relação à dissipação de calor na chapa (se funde praticamente toda a poça antes mesmo do calor começar dissipar). Esse último fato sugere que, para a formação do cordão, a relação espessura-largura da chapa não 
é um fator predominante, como foi para a ZAC (dissipação de calor na chapa). Mas observando-se melhor, para correntes maiores, houve uma tendência da penetração ser maior na chapa fina. Desta forma, ou a combinação espessura-largura afeta significantemente apenas a difusão do calor (formação da ZAC) e não a fusão (formação do cordão) ou existem fatores concorrentes. A corrente em si seria o fator dominante na formação da área fundida.

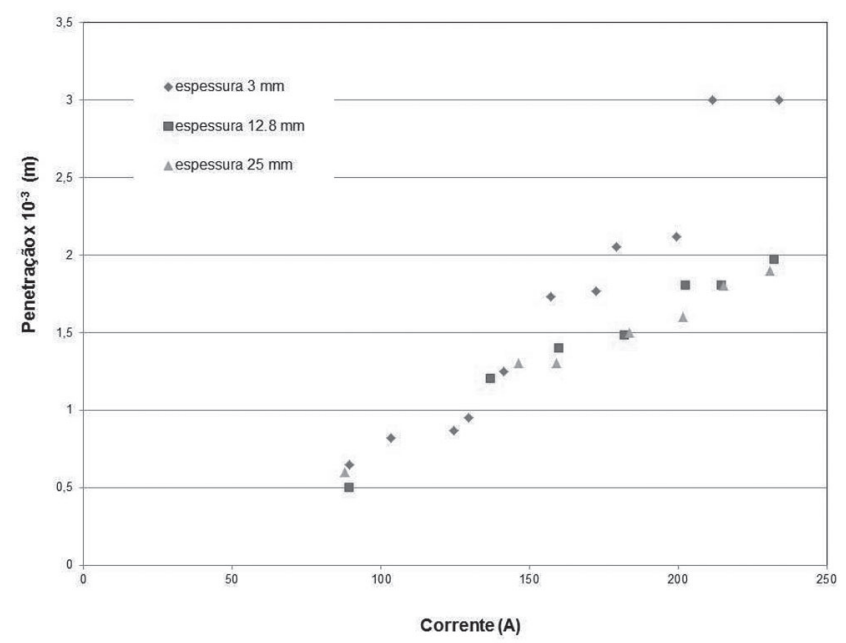

Figura 4. Penetração do cordão em função da corrente de soldagem para diferentes combinações espessura-largura de chapa

A Figura 5 ilustra a relação da corrente média com o rendimento bruto de fusão. Os resultados mostram uma tendência de se aumentar o rendimento bruto de fusão com a corrente de soldagem. Este fato já era esperado e foi concordante aos resultados encontrados por Reis et al. [6] em soldagem TIG. Esta relação se deve à intensificação dos efeitos de redução da difusão térmica com o aumento do calor imposto (saturamento térmico). Para as chapas mais finas e menos largas (3,0-38,2 $\mathrm{mm}$ ), o efeito da corrente é mais pronunciado, corroborando a justificativa acima (saturação mais fácil). Analisando a inclinação das curvas, pode-se supor que espessuras e larguras ainda maiores levariam a um crescimento de rendimento menos acentuado. Desta forma, o efeito da corrente sobre o rendimento bruto de fusão é indireto.

Assim, os autores deste trabalho acreditam existir dois fenômenos atuantes que controlam o rendimento bruto de fusão do ponto de vista térmico, ou seja, sem levar em consideração o efeito mecânico. O primeiro é o efeito da contenção da dissipação do calor (que depende da difusividade térmica do material) fornecido pelo arco. O arco sempre faz um "preaquecimento" à frente e ao redor da poça durante a soldagem, como se fosse uma barreira à dissipação do calor da poça (menor $\Delta \mathrm{T}$, mais lenta a condução de calor). Se esse preaquecimento é alto (maiores correntes), torna-se possível que o material atinja seu ponto de fusão antes do calor dissipar pelo material (maior o rendimento de fusão). Este comportamento justifica o aumento do rendimento bruto de fusão com o aumento da corrente. O segundo seria a perda de calor para dentro do próprio material por condução. Quanto maior as dimensões do material (largura e espessura), mais facilmente e rapidamente se difunde o calor fornecido pelo arco para dentro da peça, antes de acontecer a fusão (menor o rendimento bruto de fusão). Este comportamento justifica o menor rendimento bruto de fusão com o aumento das dimensões da peça. A intensidade de cada efeito vai depender das dimensões da peça, da energia de soldagem e das propriedades térmica do material.

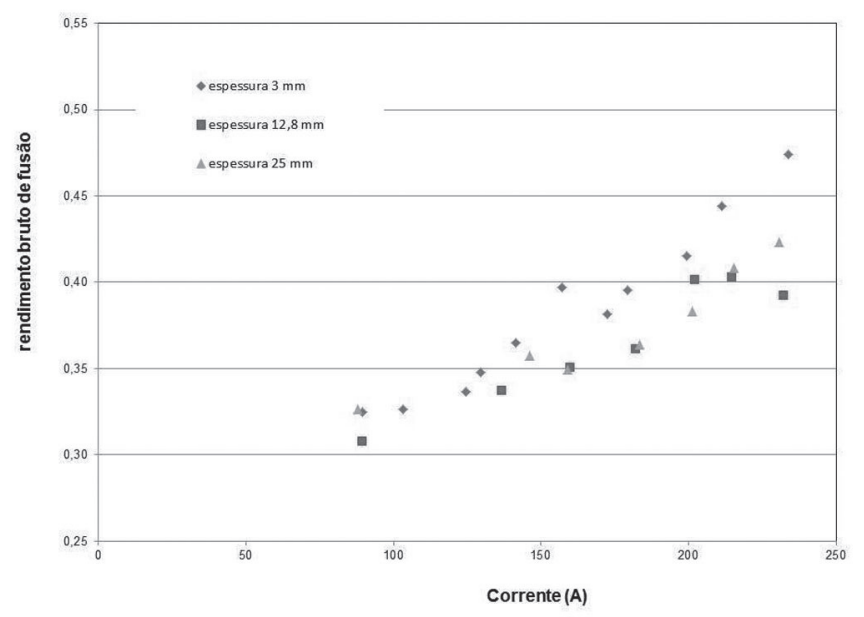

Figura 5 . Rendimento bruto de fusão em função da corrente de soldagem para diferentes combinações espessuralargura de chapa

Comparando os resultados obtidos para a menor combinação espessura-largura $(3,0-38,2 \mathrm{~mm})$ com os para maior combinação espessura-largura $(25,4-50,8 \mathrm{~mm})$ de chapas, pode-se perceber que combinações espessura-largura menores favorecem um rendimento bruto de fusão maior. Ao se utilizar chapas mais grossas, o calor cedido pelo arco para a peça possui maior quantidade de material para ser distribuído por condução, facilitando a difusão (o calor é conduzido para dentro do próprio material antes que seja utilizado para fundir o metal de base). No caso de chapas finas, pode-se adotar um modelo bidirecional para o fluxo de calor (o calor se espalha apenas no sentido longitudinal da chapa), dificultando a perda desse calor e facilitando que o mesmo seja utilizado para fundir o metal antes de difundir. Já em soldagens com chapas de maior combinação espessura-largura, um modelo tri-direcional para o fluxo de calor seria mais apropriado. Isso se reflete claramente na área da zona afetada pelo calor. Como a quantidade de material é maior, o calor é conduzido com mais facilidade em seu interior, diminuindo drasticamente a região afetada termicamente. Somente a região que se encontra mais próxima ao cordão sofreu alteração em sua microestrutura com chapas de $13 \mathrm{~mm}$ de espessura.

Em resumo, pode-se dizer que do ponto de vista térmico o rendimento bruto de fusão aumenta com o aumento da corrente (efeito 1) e que ele é maior para chapas mais finas (efeito 2). Deve-se ressaltar que esta análise só tem valor caso o efeito mecânico (pressão do jato de plasma e do momentum das gotas sobre a poça fundida) não seja importante quando se aumenta a corrente. Assim, para verificar se o efeito mecânico estava 
interferindo nos resultados acima, foi proposto estudar o efeito do ângulo de ataque (puxando, neutro e empurrando). Ao se inclinar a tocha no sentido de se fazer uma soldagem puxando, um efeito mecânico atuante tiraria a poça de fusão que se encontra entre o material de base e o arco. Assim, o calor do arco seria transferido com maior efetividade para o material base (maior rendimento bruto de fusão seria esperado). Se a poça de fusão estiver entre o arco e o material de base, haverá mais dificuldade do calor ser transferido para o metal não fundido, ocorrerá apenas o sobreaquecimento (menor rendimento de fusão). Este seria o caso de se soldar no modo empurrando.

Para tal, soldagens de simples deposição foram novamente realizadas nas mesmas condições, mas usando-se o ângulo de ataque de $-15^{\circ}$ (puxando) e $+15^{\circ}$ (empurrando). A Tabela 3 apresenta as condições experimentais aplicadas na regulagem dos parâmetros, assim como os valores monitorados, enquanto na Tabela 4 estão compilados os valores médios e respectivos desvios padrão medidos e calculados durante os testes. A Figura 6 ilustra os respectivos perfis resultantes.
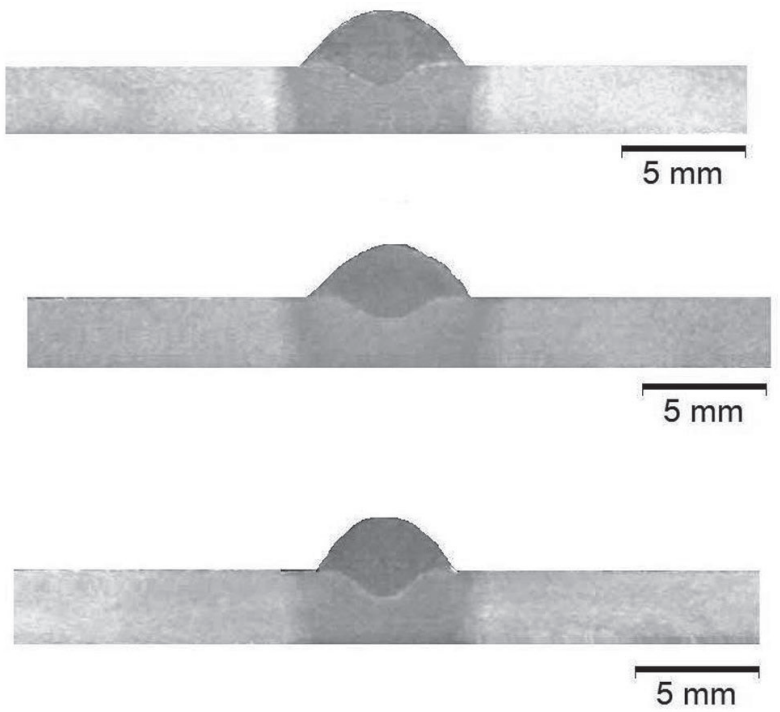

Figura 6 . Perfis típicos dos cordões produzidos por diferentes ângulos de ataque: vista de cima $=$ perpendicular; vista do meio $=$ empurrando; vista de baixo $=$ puxando

Tabela 3 . Parametrização para regulagem das soldagens e parâmetros monitorados para avaliar a influência do ângulo de ataque no rendimento bruto de fusão

\begin{tabular}{|c|c|c|c|c|c|c|}
\hline \multirow{2}{*}{ Teste } & \multicolumn{3}{|c|}{ Valor Regulado } & \multicolumn{3}{c|}{ Valor Monitorado } \\
\cline { 2 - 7 } & $\begin{array}{c}\text { Espessura-largura } \\
\text { da chapa da chapa } \\
\left(\mathrm{x} 10^{-3}\right)[\mathrm{m}]\end{array}$ & $\begin{array}{c}\text { Ângulo de } \\
\text { inclinação } \\
\text { da tocha [graus] }\end{array}$ & $\begin{array}{c}\text { Velocidade de } \\
\text { Alimentação [m/ } \\
\mathrm{min}]\end{array}$ & $\begin{array}{c}\text { Velocidade de } \\
\text { Alimentação [m/min] }\end{array}$ & $\begin{array}{c}\text { Corrente Média } \\
{[\mathrm{A}]}\end{array}$ & $\begin{array}{c}\text { Tensão Média } \\
{[\mathrm{V}]}\end{array}$ \\
\hline 19 & $3,0-38,2$ & -15 & 2,5 & 1,9 & 90.4 & 11.8 \\
\hline 18 & $3,0-38,2$ & -15 & 3,5 & 2,4 & 112.6 & 12.3 \\
\hline 17 & $3,0-38,2$ & -15 & 4,5 & 3,8 & 151.5 & 14.1 \\
\hline 16 & $3,0-38,2$ & -15 & 6,5 & 4,8 & 208.9 & 15.6 \\
\hline 23 & $3,0-38,2$ & +15 & 2,5 & 1,9 & 96.30 & 12.7 \\
\hline 22 & $3,0-38,2$ & +15 & 3,5 & 2,8 & 122.2 & 13.5 \\
\hline 21 & $3,0-38,2$ & +15 & 4,5 & 3,3 & 149.3 & 14.1 \\
\hline 20 & $3,0-38,2$ & +15 & 6,5 & 4,3 & 202.3 & 15.3 \\
\hline
\end{tabular}

Tabela 4 . Rendimento bruto de fusão e geometria dos cordões obtidos para diferentes ângulos de ataque em chapas com $3 \mathrm{~mm}$ de espessura

\begin{tabular}{|c|c|c|c|c|c|c|c|c|c|c|}
\hline \multirow{2}{*}{ Teste } & \multirow{2}{*}{$\begin{array}{c}\text { Ângulo de } \\
\text { Ataque [graus] }\end{array}$} & \multirow{2}{*}{$\begin{array}{l}\text { Corrente } \\
\text { Média [A] }\end{array}$} & \multicolumn{2}{|c|}{$\begin{array}{l}\text { Rendimento Bruto } \\
\text { de Fusão }\end{array}$} & \multicolumn{2}{|c|}{$\begin{array}{l}\text { Área transversal do } \\
\text { cordão }\left(\mathrm{x} 10^{-6}\right)\left[\mathrm{m}^{2}\right]\end{array}$} & \multicolumn{2}{|c|}{$\begin{array}{c}\text { Área da ZAC } \\
\left(\mathrm{x} 10^{-6}\right)\left[\mathrm{m}^{2}\right]\end{array}$} & \multicolumn{2}{|c|}{$\begin{array}{l}\text { Penetração } \\
\left(\mathrm{x} 10^{-3}\right)[\mathrm{m}]\end{array}$} \\
\hline & & & Média & $\begin{array}{l}\text { Desvio } \\
\text { Padrão }\end{array}$ & Média & $\begin{array}{l}\text { Desvio } \\
\text { Padrão }\end{array}$ & Média & $\begin{array}{l}\text { Desvio } \\
\text { Padrão }\end{array}$ & Média & $\begin{array}{l}\text { Desvio } \\
\text { Padrão }\end{array}$ \\
\hline 19 & -15 & 90.4 & 0,47 & 0,01 & 7,800 & 0,19 & 14,55 & 0,65 & 0,55 & 0,09 \\
\hline 18 & -15 & 112.6 & 0,53 & 0,02 & 11,26 & 0,37 & 25,29 & 0,79 & 0,96 & 0,07 \\
\hline 17 & -15 & 151.5 & 0,55 & 0,01 & 19,88 & 0,38 & 34,65 & 0,71 & 2,54 & 0,08 \\
\hline 16 & -15 & 208.9 & 0,58 & 0,02 & 24,46 & 0,86 & 34,02 & 0,63 & 3,00 & 0,12 \\
\hline 23 & +15 & 96.30 & 0,50 & 0,01 & 7,940 & 0,19 & 16,72 & 0,69 & 0,76 & 0,09 \\
\hline 22 & +15 & 122.2 & 0,53 & 0,01 & 12,45 & 0,18 & 27,34 & 0,74 & 0,86 & 0,07 \\
\hline 21 & +15 & 149.3 & 0,51 & 0,02 & 15,84 & 0,47 & 33,07 & 0,59 & 1,17 & 0,11 \\
\hline 20 & +15 & 202.3 & 0,53 & 0,01 & 21,45 & 0,43 & 37,43 & 0,80 & 1,73 & 0,08 \\
\hline
\end{tabular}


As Figuras 7 e 8 apresentam a relação entre a corrente e os parâmetros geométricos, para os diferentes ângulos de ataque. Pode-se observar que o aumento da corrente faz crescer linearmente a área da seção transversal e a penetração, confirmando os resultados anteriores. Mas no caso da área da seção transversal, o ângulo de ataque não mostrou influenciar este aspecto geométrico. Em relação ao ângulo de ataque, a condição puxando levou a uma penetração linear um pouco maior (quase desprezível). Já analisando a Figura 9, observase que não há um efeito claro do ângulo de ataque sobre o rendimento bruto de fusão. Estes resultados justificam a pouca relação entre o ângulo de ataque e a área fundida. Os resultados de forma global sugerem que a opção de se usar o MIG CMT como forma de minimizar o efeito mecânico foi atingido.

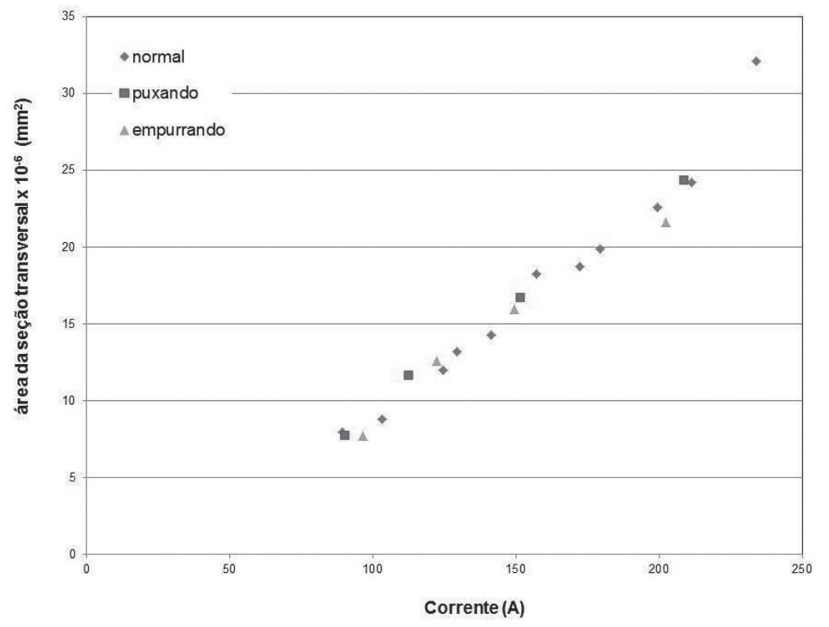

Figura 7 . Área da seção transversal do cordão em função da corrente de soldagem para diferentes ângulos de ataque

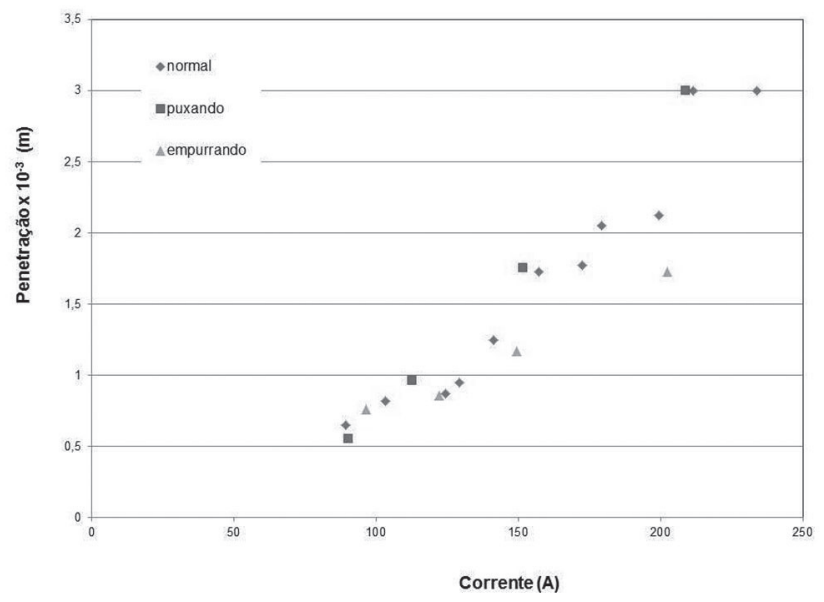

Corrente $[\mathrm{A}]$

Figura 8 . Penetração em função da corrente de soldagem para diferentes ângulos de ataque

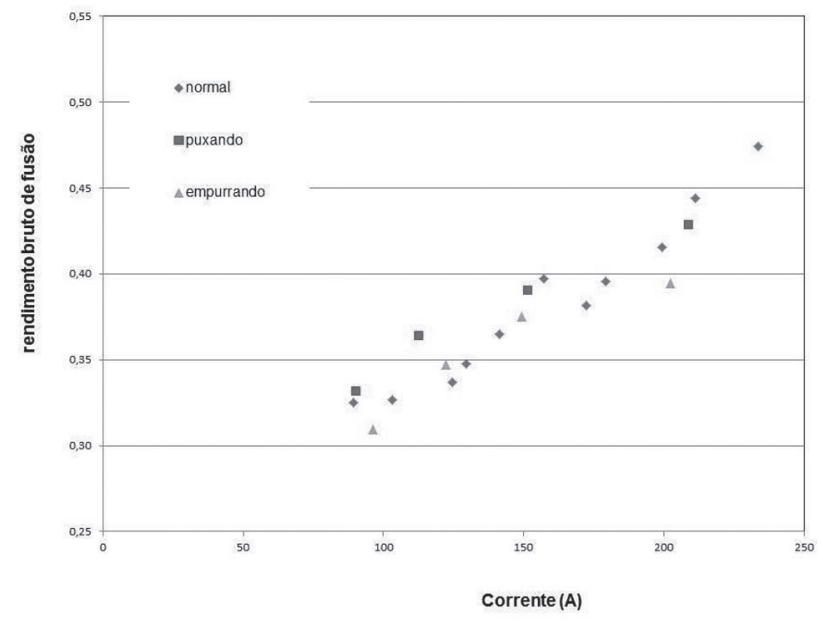

Corrente [A]

Figura 9 . Rendimento bruto de fusão em função da corrente de soldagem para diferentes ângulos de ataque

\section{Conclusões}

As principais conclusões sobre o estudo da influência da corrente média de soldagem sobre o rendimento bruto de fusão que foram apontadas ao longo do presente trabalho são:

- A metodologia desenvolvida mostrou-se capaz de minimizar o efeito mecânico do arco, permitindo que apenas o efeito térmico correspondente à corrente atuasse;

- Tanto a corrente de soldagem como a combinação espessuralargura do material afetam o rendimento bruto de fusão de forma interdependente;

- O aumento do rendimento bruto de fusão para maiores correntes se explica pelo efeito da contenção da dissipação térmica do calor fornecido pelo arco;

- O aumento do rendimento bruto de fusão para menores dimensões da peça (chapas mais finas e/ou menos largas) se justifica pela menor perda de calor para dentro do próprio material por condução.

\section{5 . Agradecimentos}

Os autores desejam agradecer à UFPR, pela disponibilização laboratorial, e ao CNPq, tanto pelas bolsas de pesquisa a seus autores, como pelo apoio financeiro através do projeto n $478093 / 2012-8$

\section{Referências Bibliográficas}

[1] AWS, Standard Welding: terms and Definitions, Standard AWS A3.0:2001, Jul 2001.

[2] SCOTTI, A.; REIS, R.P. E LISKEVYCH, O., Modelo descritivo do fluxo de calor em soldagem a arco visando o conceito de calor imposto efetivo. Soldag. insp. [online]., vol.17, n.2, 2012, pp. 166-172. ISSN 0104-9224. http://dx.doi. 
org/10.1590/S0104-92242012000200010.

[3] SCHWEDERSKY, M.B., DUTRA, J.C., OKUYAMA, M.P., SILVA, R.H.G., Soldagem TIG de Elevada Produtividade: Influência dos Gases de Proteção na Velocidade Limite para Formação de Defeitos, Soldagem \& Inspeção, vol. 16, n. 4, Oct./ Dec. 2011, ISSN 0104-9224, http://dx.doi.org/10.1590/S010492242011000400004

[4] SCOTTI, A., PONOMAREV, V., Soldagem MIG/MAG melhor entendimento, melhor desempenho, Ed. Artliber Editora, $1^{\text {a }}$. Edição, 2008, 284 p., ISBN: 85-88098-42-8

[5] SCOTTI, A. \& RODRIGUES, C.E.A.L., Determination of momentum as a mean of quantifying the mechanical energy delivered by droplets during MIG/MAG welding, Eur. Phys. J. Appl. Phys. 45 (1), 2009, pp 11201, p1-p8, DOI: 10.1051/ epjap:2008196 (ISSN: 1286-0042; e-ISSN: 1286-0050)

[6] REIS, R.P.; COSTA, A.L.G.; SILVEIRA, F.M.; MOTA, P.R.; SOUZA, R.J.; SCOTTI, A., Influência do Material de Base sobre o Rendimento de Fusão em Soldagem a Arco, Soldagem \& Inspeção, Vol. 16, No. 4, p. 369-376, Out/Dez 2011 (ISSN 0104-9224 printed/ISSN 1980-6973 on-line), doi: 10.1590/ S0104-92242011000200007

[7] NASCIMENTO, A.S, BATISTA, M.A., NASCIMENTO, V.C., SCOTTI, A., Avaliação dos Métodos de Cálculo de Potência Elétrica em Soldagem a Arco e as Conseqüências sobre as Previsões Geométricas, Térmicas e Metalúrgicas da Junta, Soldagem \& Inspeção, Vol. 12, No 2 (Abr/Jun), 2007, pp. 97 106 (ISSN 0104-9224 printed/ISSN 1980-6973 on-line) 